\title{
Evaluation of Antioxidant Activity of Botto-Botto Leaf Fraction (Chromolaena Odorata L.) Using DPPH and ABTS Methods
}

\author{
Karlina Amir Tahir ${ }^{1,5 *}$, Upik A. Miskad ${ }^{2}$, Khairuddin Djawad $^{3}$, Sartini Sartini ${ }^{4}$, Natsir Djide ${ }^{4}$, Khaerani Khaerani $^{1}$, Maulita Indrisari $^{5}$ \\ ${ }^{1}$ Department of Pharmacy, Faculty of Medicine and Health Sciences, UIN Alauddin Makassar, Indonesia; ${ }^{2}$ Department of \\ Anatomical Pathology, Faculty of Medicine, Universitas Hasanuddin, Makassar, Indonesia; ${ }^{3}$ Department of Dermatology and \\ Venereology, Faculty of Medicine, Universitas Hasanuddin, Makassar, Indonesia; ${ }^{4}$ Faculty of Pharmacy, Universitas Hasanuddin, \\ Makassar, Indonesia; ${ }^{5}$ Postgraduate Doctoral Program, Faculty of Medicine, Universitas Hasanuddin, Makassar, Indonesia
}

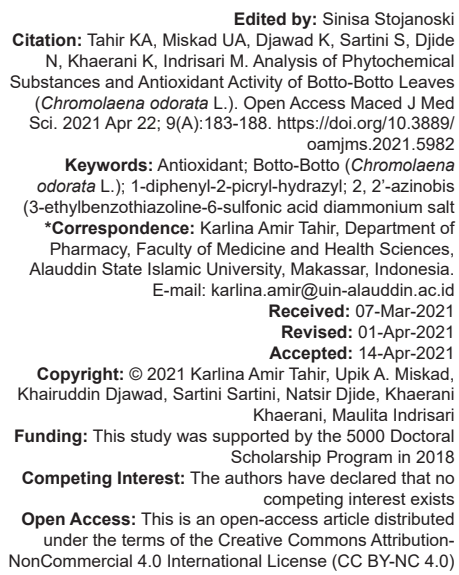

\section{Abstract}

BACKGROUND: Antioxidants are substances that can inhibit the oxidation process, so that they have a protective effect on cells from the dangers of free radicals. One of the plants that has activity as natural antioxidants is BottoBotto leaves (Chromolaena odorata L.).

AIM: This study aims to determine the antioxidant activity of the Botto-Botto leaf fraction using the DPPH and ABTS methods.

METHODS: The leaves of Botto-Botto (Chromolaena odorata L.) obtained from Takalar District, South Sulawesi are sorted, dried and pollinated. The powder was immersed in $70 \%$ ethanol solvent and sonicated. Furthermore, the extraction was carried out by maceration method with $70 \%$ ethanol solvent and fractionated using water, $\mathrm{n}$-hexane, and $n$-butanol as solvents and dried. The fractionation results were continued for antioxidant testing using the DPPH and ABTS methods.

RESULTS: The n-butanol fraction of Botto-Botto leaves had the highest antioxidant activity, namely the strong active category. In the DPPH and ABTS methods, the n-butanol fraction has IC50 values of $33.535 \mu \mathrm{g} / \mathrm{mL}$ and $60.885 \mu \mathrm{g} / \mathrm{mL}$, respectively.

CONCLUSION: The DPPH and ABTS methods, the n-butanol fraction of botto-botto leaves have strong antioxidant activity compared to other fractions, namely the water fraction and the $\mathrm{n}$-hexane fraction.

\section{Introduction}

The medicinal properties of plants are caused by the active chemical elements present in various plant parts. This chemical element has a physiological effect on the human body. The most important bioactive compounds from plants are alkaloids, flavonoids, tannins, and phenolics. Phytochemical research based on ethnopharmacological information is generally considered a practical approach to discovering new antioxidants from higher plants [1], [2], [3].

Antioxidants are broadly defined as substances that inhibit the oxidation process from protecting cells from the dangers of free radicals that arise from body metabolism or other external factors. Chemically, natural antioxidants found in plants and foodstuffs are mainly derived from phenol-derived compounds such as flavonoids (quercetin) [4], [5], [6]. Chromolaena odorata (Family: Asteraceae) is synonymous with Eupatorium odoratum, a traditional medicinal plant widely used for its wound healing properties. Some parts of this plant have been used to treat wounds, burns, and skin infections [7]. Furthermore, this plant has been shown to have an anticancer, antidiabetic, antihepatotoxic, anti-inflammatory, antimicrobial, and antioxidant profile [8]. The phytochemical components are alkaloids, flavonoids, flavanones, essential oils, phenolics, saponins, tannins, and terpenoids. Other important constituents of this plant are Eupolin, chromomoric acid, quercetin, and quercetin. The efficiency of wound healing comes from the drug or plant's antioxidant properties, which increase the preservation of fibroblasts and the proliferation of keratinocytes in the wound [9], [10], [11].

Oxidation is an essential process in living things. Free radicals are produced from metabolic pathways or environmental sources that interact continuously with biological systems. Reactive oxygen species (ROS) are the most significant primary catalysts that initiate the oxidation process in vivo and in vitro and generate oxidative stress [12]. Antioxidants have the ability to destroy free radicals and maintain body cells, including immune cells, from oxidation stress. The potential antioxidant effects of these plants are 
significant. It is shown that evidence suggests that oxidative stress is induced by ROS. ROS play a key role in the etiology and development of several human diseases. Oxidative stress is one of the reasons that are thought to be involved in almost every disease process. Free radicals are the leading cause of various chronic and degenerative diseases, including aging, coronary heart disease, inflammation, stroke, diabetes mellitus, and cancer [15].

The need for antioxidants is increasing due to the development of various diseases that require appropriate therapy and do not cause dangerous side effects. The discovery of the antioxidant profile can be scientific evidence for developing natural ingredients into a solution for a disease or metabolic disorder in humans. This study aims to analyze the phytochemical substances and antioxidant power of the Botto-Botto leaf.

\section{Methods}

\section{Design, place, and time}

This research was laboratory research with qualitative and quantitative approaches. This research was designed as pure experimental research (True Experimental). Post-test only control design was carried out from May 2019 to September 2019 in the laboratory, the Botanical Field Herbarium Center for Botany Biological Research Center of the Indonesian Institute of Sciences (LIPI) Bogor, and Biopharmaca Laboratory (Research Activity Center) Hasanuddin University Makassar.

\section{Instruments and materials}

The tools used are maceration tools, test kits for chemical content, glass tools, UV-Vis spectrophotometer $\left(\right.$ Agilent $^{\circledR}$ ), ELISA reader (Biotek ${ }^{\circledR}$ ), and analytical scales. The materials used were the leaves of Botto-Botto (Chromolaena odorata L.), ethanol (Merck), N-hexane (Merck), Aquadest (Merck), ascorbic acid (Merck), 1-diphenyl-2-picrylhydrazyl (DPPH) (Sigma-Aldrich), 2, 2'-azinobis (3-ethylbenzothiazoline-6-sulphonic acid diammonium salt) (ABTS) (Sigma-Aldrich).

\section{Research procedure}

\section{Plant determination}

Plant determination was carried out at the Botanical Field Herbarium Bogoriense Center, Center for Biological Research, the Indonesian Institute of Sciences (LIPI), Bogor. All parts of the Botto-Botto plant (Chromolaena odorata L.) were used in the determination process.

\section{Sample processing}

Extraction and Fractionation

The leaves of Botto-Botto (Chromolaena odorata L.) obtained from Takalar District, South Sulawesi, are cleaned, dried, and pollinated. The powder was immersed in $70 \%$ ethanol solvent and sonicated using a sonicator $(E I m a ®)$ for 15 minutes. Extraction was carried out with $70 \%$ ethanol solvent three times until the filtrate became clear. The concentrated filtrate was evaporated at a rotary evaporator and dried using desiccator. The extract was then fractionated using water, n-hexane, and n-butanol solvents and dried using a freeze dryer Lyophilizer (Büchi L200, Germany).

\section{Phytochemical Screening of Botto-Botto Leaf} Extract Fraction (Chromolaena odorata L.)

Screening using the TLC method with $10 \%$ $\mathrm{AICl} 3$ spray reagent for identification of flavonoid compounds and $10 \% \mathrm{FeCl} 3$ for identification of phenolic compounds. The eluent used was ethyl acetate: methanol with a ratio of $5: 1$. The spots were observed using UV $254 \mathrm{~nm}$ and $366 \mathrm{~nm}$.

\section{Quantitative test of chemical content of Botto-Botto (Chromolaena odorata I.) leaf extract fraction}

Total flavonoid levels were tested using quercetin standards and total polyphenol levels using gallic acid standards.

\section{Antioxidant activity test of Botto-Botto leaf extract fraction}

DPPH methods

Preparation of DPPH solution

Weighed $8 \mathrm{mg}$ DPPH put in a brown bottle then dissolved in $50 \mathrm{ml}$ ethanol p.a. After DPPH dissolves, it was wrapped in aluminum foil and stored in a dark place away from sunlight.

Preparation of ascorbic acid solution (positive control)

Ascorbic acid dilution was made of 1, 2, 3, 4, $5 \mu \mathrm{g}$ / $\mathrm{mL}$ and put in the vial, then dissolved p.a ethanol gradually until the quercetin dissolves. Wrapped in aluminum foil and stored in a dark place away from sunlight.

Antioxidant activity test

Determination of the ability of free radical scavenging from leaf extract was carried out by using the DPPH a-diphenyl- $\beta$-picryl-hydrazine test. This method is based on reducing DPPH in a methanol 
solution in the presence of the donation of antioxidant hydrogen to form non-radical DPPH-H. The reduction of free radicals results in color changes as measured by spectroscopy. The reaction mixture $(3.0 \mathrm{~mL})$ consisted of $1.0 \mathrm{~mL}$ of DPPH in methanol $(0.3 \mathrm{mM}), 1.0 \mathrm{~mL}$ of extract, and $1.0 \mathrm{~mL}$ of methanol. The reaction mixture $(3.0 \mathrm{~mL})$ consisted of $1.0 \mathrm{~mL}$ of DPPH in methanol $(0.3 \mathrm{mM})$, $1.0 \mathrm{~mL}$ of extract and $1.0 \mathrm{~mL}$ of methanol. The reaction mixture was incubated for 10 minutes in the dark before absorbance was measured at a wavelength of $516 \mathrm{~nm}$ using ascorbic acid as a comparison. Five concentrations were made for each fraction and measured in triplo.

Antioxidant activity was expressed by the percentage of free radical binding with the formula:

free radical binding $=(($ blank absorption - sample absorption $) /($ blank absorption $)) * 100 \%$

\section{ABTS Methods}

The samples were diluted to yield five concentrations suitable for calculating IC50. Into the well plate was inserted into the sample (five concentrations), added with ABTS $100 \mu \mathrm{L}$ solution and the volume was sufficient to $200 \mu \mathrm{L}$ with ethanol p.a so that the concentration of each sample fraction $\mu \mathrm{g} / \mathrm{mL}$ was obtained, then incubated for 30 minutes at room temperature. The absorbance is read at a maximum wavelength of $650 \mathrm{~nm}$ and the percentage of inhibition is calculated. Testing of each sample concentration was carried out triplo. The inhibition is calculated according to the equation:

$\%$ ABTS radical binding $=(($ control absorption sample absorption) / (control absorption) $) * 100 \%$.

\section{Results}

Identification of Botto-Botto leaves contained phenolic and flavonoids in three samples which were checked with positive results (Table 1).

Table 1. Identification Results of Botto-Botto Leaf Fraction Compound Components

\begin{tabular}{llll}
\hline Compound & Information & & \\
\cline { 2 - 4 } & Water fraction & n-butanol fraction & n-hexane fraction \\
\hline Phenolic & + & + & + \\
Flavonoids & + & + & + \\
\hline Note: Present (+), Absent (-) & &
\end{tabular}

The flavonoid testing standard found the highest concentration in quercetin 5 with an absorption of 1071 (Table 2).

Table 2: Flavonoid testing standards

\begin{tabular}{lll}
\hline Samples & Concentration $(\mathrm{ppm})$ & Absorbances \\
\hline Blank & 0.0 & 0.000 \\
Quercetin 1 & 2.0 & 0.251 \\
Quercetin 2 & 4.0 & 0.408 \\
Quercetin 3 & 6 & 0.606 \\
Quercetin 4 & 8 & 0.831 \\
Quercetin 5 & 10 & 1.071 \\
\hline
\end{tabular}

Quercetin standard curve shows that the higher the concentration of quercetin, the higher the absorption of quercetin (Figure 1).

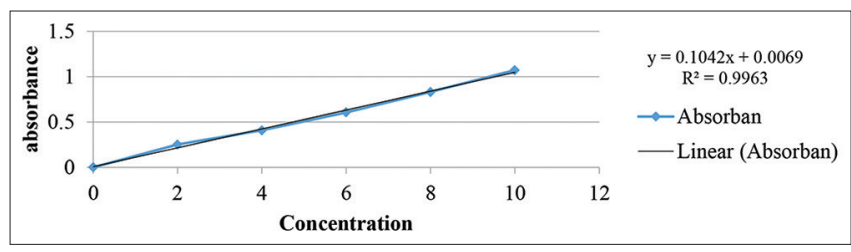

Figure 1: Quercetin standard curve for testing of flavonoids

The flavonoid test standard found the highest concentration in gallic acid 6 with absorption capacity of 1074 (Table 4).

Table 4: Polyphenol testing standards

\begin{tabular}{lll}
\hline Samples & Concentration & Absorbance \\
\hline Blank & 0.0 & 0.000 \\
Gallic acid 1 & 2.0 & 0.179 \\
Gallic acid 2 & 4.0 & 0.409 \\
Gallic acid 3 & 6.0 & 0.558 \\
Gallic acid 4 & 8.0 & 0.686 \\
Gallic acid 5 & 10.0 & 0.887 \\
Gallic acid 6 & 12.0 & 1.074 \\
\hline
\end{tabular}

Standard curve of gallic acid shows that the more the concentration of gallic acid, the more its absorption (Figure 2).

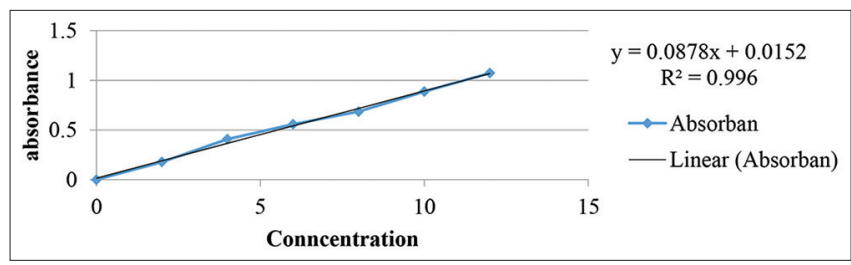

Figure 2: Standard curves of gallic acid for polyphenols

Flavonoid levels in the sample showed that of the three samples tested on insoluble hexane with an average of 7.06 , the highest level of flavonoids was in the insoluble hexane 1 sample (7.40). In three samples of soluble hexane with an average of 0.92 , the highest level of flavonoids was in soluble hexane sample 3 (0.95), in three flavonoid extract samples with an average of 2.70 , the highest level of flavonoids was in sample extract 2

Table 3 Levels of Total Sample Flavonoids

\begin{tabular}{|c|c|c|c|c|c|c|}
\hline Samples & Absorbances & Flavonoid concentration $(\mu \mathrm{g} / \mathrm{mL})$ & Sample weight (mg) & Dilution factor & Flavonoid levels (\%) & Average Flavonoid levels (\%) \\
\hline Ethanol Extract & 0,280 & 2,618 & 10,1 & 10,00 & 2,59 & 2,70 \\
\hline Ethanol Extract & 0,307 & 2,877 & 10,3 & 10,00 & 2,79 & \\
\hline Ethanol Extract & 0,290 & 2,713 & 10,0 & 10,00 & 2,71 & \\
\hline n- Hexan fraction & 0,102 & 0,915 & 10,1 & 10,00 & 0,91 & 0,92 \\
\hline n- Hexan fraction & 0,103 & 0,922 & 10,2 & 10,00 & 0,90 & \\
\hline n- Hexan fraction & 0,108 & 0,967 & 10,2 & 10,00 & 0,95 & \\
\hline n-Butanol fraction & 0,785 & 7,470 & 10,1 & 10,00 & 7,40 & \\
\hline n-Butanol fraction & 0,742 & 7,051 & 10,3 & 10,00 & 6,85 & 7,06 \\
\hline n-Butanol fraction & 0,745 & 7,081 & 10,2 & 10,00 & 6,94 & \\
\hline Water fraction & 0,104 & 0,931 & 10,1 & 10,00 & 0,92 & 1,00 \\
\hline Water fraction & 0,116 & 1,043 & 10,3 & 10,00 & 1,01 & \\
\hline Water fraction & 0,118 & 1,065 & 10,0 & 10,00 & 1,07 & \\
\hline
\end{tabular}


Table 5 Total Polyphenol Levels in Samples

\begin{tabular}{|c|c|c|c|c|c|c|}
\hline Samples & Absorbances & Polyphenol concentration $(\mu \mathrm{g} / \mathrm{mL})$ & Sample weight (mg) & Dilution factor & Polyphenols levels (\%) & Average polyphenol levels (\%) \\
\hline Ethanol Extract & 0,571 & 6,334 & 10,1 & 16,67 & 10,45 & 10,56 \\
\hline Ethanol Extract & 0,591 & 6,558 & 10,3 & 16,67 & 10,61 & \\
\hline Ethanol Extract & 0,574 & 6,363 & 10,0 & 16,67 & 10,61 & \\
\hline $\mathrm{n}$ - Hexan fraction & 0,748 & 8,353 & 10,1 & 16,67 & 13,78 & 14,30 \\
\hline n- Hexan fraction & 0,818 & 9,153 & 10,2 & 16,67 & 14,96 & \\
\hline n- Hexan fraction & 0,776 & 8,672 & 10,2 & 16,67 & 14,17 & \\
\hline n-Butanol fraction & 0.97 & 10.882 & 10.1 & 16.67 & 17.96 & 18,08 \\
\hline n-Butanol fraction & 0.991 & 11.119 & 10.3 & 16.67 & 17.99 & \\
\hline n-Butanol fraction & 0,998 & 11.200 & 10.2 & 16.67 & 18.30 & \\
\hline Water fraction & 0,634 & 7,055 & 10,1 & 16,67 & 11,64 & 11,87 \\
\hline Water fraction & 0,661 & 7,353 & 10,3 & 16,67 & 11,90 & \\
\hline Water fraction & 0,651 & 7,248 & 10,0 & 16,67 & 12,08 & \\
\hline
\end{tabular}

(2.79), in three water-soluble flavonoid samples with an average of 1.00 , the level of flavonoids was the highest in water-soluble samples 3 (1.07) (Table 3).

Polyphenol levels in the sample showed that of the three samples tested on insoluble hexane with an average of 18.08 , the highest polyphenol content was found in hexane insoluble samples 2 (17.99). In three dissolved hexane samples with an average of 14.30 , the highest polyphenol content was found in dissolved hexane sample 2 (14.96). In three samples of polyphenol extracts with an average of 10.56 , the highest polyphenol extracts were found in extract samples 2 and 3 (10.61). In three samples of water-soluble polyphenols with an average of 11.87 , the highest polyphenol content was in water-soluble samples 3 (12.08), (Table 5).

The results of this study were expressed in antioxidant profile $\left(\mathrm{IC}_{50}\right)$. The antioxidant profile of BottoBotto leaves based on the DPPH and ABTS methods is described in the following Tables 6 and 7:

The results of the antioxidant profile $\left(\mathrm{IC}_{50}\right)$ with the DPPH method were the highest in sample $B$ (80,249 ppm) (Table 6).

The results of the antioxidant profile $\left(\mathrm{IC}_{50}\right)$ with the ABTS method were the highest in sample $B$ (156.037 ppm) (Table 7).

\section{Discussion}

The sample used was Botto-Botto's (Chromolaena odorata $(L)$ ) leaves, which were identified scientifically at LIPI, Bogor. The type of Chromolaena odorata $(L)$ R. M. King and H. Rob were included in this study. The existence of this termination was to clarify further the type of sample used in the study.

Table 6. IC50 value on the DPPH Method

\begin{tabular}{ll}
\hline Samples & IC50 $(\mu \mathrm{g} / \mathrm{mL})$ \\
\hline Water fraction & 47.232 \\
N-Heksan fraction & 80.249 \\
N-Butanol fraction & 33.535 \\
Ascorbic acid & 3.905 \\
\hline
\end{tabular}

The measurement of antioxidant activity was carried out on the Botto-Botto leaf extract fraction. The antioxidant activity was determined using the DPPH (1,1-diphenyl-2-picrylhydrazine) method. DPPH acts as a free radical that will react with antioxidants to form DPPH-H (1,1-diphenyl-2-picrylhydrazine). Antioxidants will donate their hydrogen atoms to DPPH radicals to complement the electron deficiency and form more stable antioxidant radicals. Apart from $\mathrm{DPPH}$, the method used in this study was ABTS [16], [17]. It is a method of determining antioxidant activity obtained from potassium oxidation persulfate with diammonium ABTS salt. In this method, the antioxidant mechanism occurs by donating proton radicals.

Table 7: $\mathrm{IC}_{50}$ profile on the ABTS method

\begin{tabular}{ll}
\hline Samples & $\mathrm{IC}_{50}(\mathrm{ppm})$ \\
\hline $\mathrm{A}$ & 114.233 \\
$\mathrm{~B}$ & 156.037 \\
$\mathrm{C}$ & 60.885 \\
Ascorbic acid & 4.869 \\
\hline
\end{tabular}

The presence of the sample's antioxidant activity is indicated by the loss of blue color in the ABTS reagent [18]. These two analysis methods are common tests for antioxidant measurements. The advantage of ABTS over DPPH is the higher sensitivity to ABTS and can be applied for testing food antioxidants.

Flavonoids contain a conjugated aromatic system that will show a strong absorption band in UV and visible light. In the TLC analysis and the appearance with AICl3 10\% flavonoid reagent will appear yellow spots and depending on the structure. For phenolic compounds, a bluish black spot will appear at $366 \mathrm{~nm}$ UV which indicates a positive result. Phytochemical screening of samples of n-hexane fraction, n-butanol fraction and water fraction showed positive results on the flavonoid compound test. and phenolic. Meanwhile, the total flavonoid and total polyphenol content test showed that the highest levels were in the n-butanol fraction, respectively, namely $7.06 \%$ and $18.08 \%$. Flavonoids and polyphenols are closely related to the antioxidant effect shown by the leaves of Botto-Botto. The antioxidant capacity of these compounds is closely related to electron donation. The electron donation activity reflects the reducing power of bioactive compounds, which means that it is related to antioxidant activity. These results indicate the potential of the n-butanol fraction in its role as an antioxidant that can reduce free radicals.

Measurement of antioxidant activity was carried out on n-hexane fraction, n-butanol fraction and water fraction from botto-botto leaves. In the DPPH method, the measurement of the antioxidant activity of the botto-botto leaf extract fraction which is included in 
$10-50 \mu \mathrm{g} / \mathrm{mL}$ ) is an IC50 value of $47,232 \mu \mathrm{g} / \mathrm{mL}$ in the water fraction and $33,535 \mu \mathrm{g} / \mathrm{mL}$ in fraction $\mathrm{n}$. -butanol while the $\mathrm{n}$-hexane fraction is moderately active (range of IC50 values $50-100 \mu \mathrm{g} / \mathrm{mL}$ ) with an IC50 value of $80.249 \mu \mathrm{g} / \mathrm{mL}$.

The test using the ABTS method, the IC50 value with an IC50 value range of $50-100 \mu \mathrm{g} / \mathrm{mL}$ was included in the strong antioxidant category. The n-butanol fraction includes strong antioxidants with an IC50 value of $60.885 \mu \mathrm{g} / \mathrm{mL}$, the water fraction IC50 value of $114.233 \mu \mathrm{g} / \mathrm{mL}$ is included in the moderate antioxidant activity group (IC50 value range 101-150 $\mu \mathrm{g}$ / $\mathrm{mL}$ ), and the h-hexane fraction IC50 value is $\mathbf{1 5 6 . 0 3 7}$ $\mu \mathrm{g} / \mathrm{mL}$ including the group of weak antioxidant activity (range IC50 values $150-200 \mu \mathrm{g} / \mathrm{mL}$ ). The test results from DPPH and ABTS show that botto-botto leaves have the potential as a source of natural antioxidant compounds and the n-butanol fraction has stronger antioxidant activity than other fractions, namely the $\mathrm{n}$-hexane fraction and the water fraction because it has an IC50 value that is in the range. strong category.

Furthermore,phytochemical screening was carried out to screen Botto-Botto leaves' content. From this process, alkaloids, flavonoids, polyphenols, coumarins, and organic compounds were obtained. Alkaloids, flavonoids, and polyphenols are closely related to the antioxidant effect shown by Botto-Botto leaves. The antioxidant capacity of these compounds is closely related to electron donation. The presence of electron donation activity reflects the reduction power of bioactive compounds, which means that it is related to antioxidant activity. It has been found in many previous studies [19], [20]. With the results shown, the Botto-Botto leaves have the potential as antioxidants. The limitation of this research is that in this study, the isolation of pure compounds has not been carried out so that it is not known what flavonoid compounds act as antioxidants and their antioxidant ability is tested to be compared with other fractions.

\section{Conclusion}

The results showed that the n-butanol fraction from the leaf extract of Botto-Botto (Chromolaena odorata $L$ ) had the highest antioxidant activity compared to the $n$-hexane fraction and water fraction, where in the DPPH method the IC50 value of the n-butanol fraction was $33.535 \mu \mathrm{g} / \mathrm{mL}$ and in the ABTS method the IC50 value was $60.885 \mu \mathrm{g} / \mathrm{mL}$. This antioxidant property is influenced by the presence of flavonoid and phenolic compounds in the leaves of the botto-botto. Therefore, this $n$-butanol fraction has the potential as a source of natural antioxidants used in pharmaceutical preparation formulations.

\section{Acknowledgment}

Thanks to the 5000 Doctoral Scholarship Program in 2018, the Ministry of Religion of the Republic of Indonesia gave the author confidence to receive doctoral level education scholarships.

\section{References}

1. Bernhoft A. A brief review on bioactive compounds in plants. In: Bioactive Compounds in Plants-Benefits and Risks for Man and Animals. Vol. 50. The Norwegian Academy of Science and Letters; 2010. p. 11-7.

2. Puri B, Hall A. Phytochemical Dictionary: A Handbook of Bioactive Compounds from Plants. Boca Raton: CRC Press; 1998.

3. Sasidharan S, Chen Y, Saravanan D, Sundram KM, Latha LY Extraction, isolation and characterization of bioactive compounds from plants' extracts. Afr J Tradit Complement Altern Med. 2011;8(1):1-10. https://doi.org/10.4314/ajtcam.v8i1.60483 PMid:22238476

4. Das S, Bora N, Rohman MA, Sharma R, Jha AN, Roy AS. Molecular recognition of bio-active flavonoids quercetin and rutin by bovine hemoglobin: An overview of the binding mechanism, thermodynamics and structural aspects through multi-spectroscopic and molecular dynamics simulation studies. Phys Chem Chem Phys. 2018;20(33):21668-84. https://doi. org/10.1039/c8cp02760a

5. Jan AT, Azam M, Siddiqui K, Ali A, Choi I, Haq QM. Heavy metals and human health: Mechanistic insight into toxicity and counter defense system of antioxidants. Int $\mathrm{J}$ Mol Sci. 2015;16(12):29592-630. https://doi.org/10.3390/ijms161226183 PMid:26690422

6. Maesaroh K, Kurnia D, Anshori JA. Comparison of the antioxidant activity test methods of DPPH, FRAP and FIC against ascorbic acid, gallic acid and quercetin. Chim Nat Acta. 2018;6(2):93-100. https://doi.org/10.24198/cna.v6.n2.19049

7. Zachariades C, Day M, Muniappan R, Reddy GV. Chromolaena odorata (L.) king and robinson (Asteraceae). In: Biological Control of Tropical Weeds using Arthropods. Cambridge: Cambridge University Press; 2009. p. 130-62. https://doi. org/10.1017/cbo9780511576348.008

8. Adedapo AA, Oyagbemi AA, Fagbohun OA, Omobowale TO, Yakubu MA. Evaluation of the anticancer properties of the methanol leaf extract of Chromolaena odorata on HT-29 cell line. J Pharmacogn Phytochem. 2016;5(2):52.

9. Parameswari G, Suriyavathana M. In vitro antioxidant activity of Chromolaena odorata (L.) King and Robinson. Int Res J Pharm. 2012;3(11):187-92.

10. Pitakpawasutthi $\mathrm{Y}$, Thitikornpong $\mathrm{W}$, Palanuvej $\mathrm{C}$, Ruangrungsi N. Chlorogenic acid content, essential oil compositions, and in vitro antioxidant activities of Chromolaena odorata leaves. J Adv Pharm Technol Res. 2016;7(2):37-42. https://doi. org/10.4103/2231-4040.177200

PMid:27144150

11. Usunomena U, Efosa EG. Phytochemical analysis, minera composition and in vitro antioxidant activities of Chromolaena odorata leaves. ARC J Pharm Sci. 2016;2(2):16-20. https://doi. 
org/10.20431/2455-1538.0202003

12. Mhamdi A, Breusegem FV. Reactive oxygen species in plant development. Development. 2018;145(15):dev164376. https:// doi.org/10.1242/dev.164376

PMid:30093413

13. Kinnula VL, Crapo JD. Superoxide dismutases in malignant cells and human tumors. Free Radic Biol Med. 2004;36(6):718-44. https://doi.org/10.1016/j.freeradbiomed.2003.12.010 PMid:14990352

14. Sies H, Jones DP. Reactive oxygen species (ROS) as pleiotropic physiological signalling agents. Nat Rev Mol Cell Biol. 2020;21(7):363-83. https://doi.org/10.1038/s41580-020-0230-3 PMid:32231263

15. Slater TF. Free radical mechanisms in tissue injury. In: Cell Function and Disease. Berlin: Springer; 1988. p. 209-18.

16. Sridhar $\mathrm{K}$, Charles $\mathrm{AL}$. In vitro antioxidant activity of Kyoho grape extracts in DPPH and ABTS assays: Estimation methods for EC50 using advanced statistical programs. Food Chem.
2019;275:41-9. https://doi.org/10.1016/j.foodchem.2018.09.040 PMid:30724215

17. Yeo J, Shahidi F. Revisiting DPPH (2, 2-diphenyl-1picrylhydrazyl) assay as a useful tool in antioxidant evaluation: A new IC100 concept to address its limitations. J Food Bioact. 2019;7: 36-42. https://doi.org/10.31665/jfb.2019.7196

18. Molyneux P. The use of the stable free radical diphenylpicrylhydrazyl (DPPH) for estimating antioxidant activity. Songklanakarin J Sci Technol. 2004;26(2):211-9.

19. Handayany GN, Umar I, Ismail I. Formulation and test of the antioxidant effectiveness of the botto'-botto '(Chromolaena odorata L.) leaf ethanol extract cream using the DPPH method. J Kesehatan. 2018;11(2):86- 90. https://doi.org/10.24252/ kesehatan.v11i2.5944

20. Rusdi M, Haeria H, Hamzah N, RaufA, Amriani F. Antiproliferation potential of botto-botto (Chromolaena odorata L.) leaves methanol extract fraction against HeLa cell line. Ad-Dawaa' J Pharm Sci. 2020;3(1):83-9. 